\title{
Applicability of the Surface Water Extraction Methods Based on China's GF-2 HD Satellite in Ussuri River, Tonghe County of Northeast China
}

\author{
Wenfeng Gong*, Tiedong Liu*†, Yan Jiang** and Philip Stott*** \\ *College of Forestry, Hainan University, Haikou 570228, China \\ **College of Hydraulic and Electrical Engineering, Heilongjiang University, Harbin 150086, China \\ ***School of Animal and Veterinary Sciences, The University of Adelaide, Roseworthy 5371, Australia \\ †Corresponding author: Tiedong Liu; 54626320@qq.com
}

Nat. Env. \& Poll. Tech.

Website: www.neptjournal.com

Received: 03-12-2019

Revised: 20-12-2019

Accepted: 01-03-2020

Key Words:

Surface water extraction

GF-2 satellite

Water index

Support vector machine

\begin{abstract}
Surface water is the most important and common water resource on earth. Accurate and effective mapping and detecting of surface water have been made possible by remote sensing technology, highresolution satellite data, playing an important role in surface water monitoring and mapping, which has become the current hot research for water information extraction in recent decades. Therefore, in this paper, we tested and analysed four models to extract water bodies using China's GF-2 HD satellite (GF2) image, including Normalized Difference Water Index (NDWI), Modified Shadow Water Index (MSWI), Support Vector Machine (SVM) and Object-Oriented Method (OOM). The results showed applying water extraction models can map surface water with an overall accuracy of $0.8935,0.9256,0.9467$ and 0.9357 , respectively. SVM owns the highest overall accuracy value of 0.9467 , followed by OOM. SVM performed significantly better at surface water extraction with kappa coefficients improved by $9.00 \%$, $5.00 \%$, and $2.00 \%$, respectively, which yielded the best results and used to map surfaces water bodies in the study region, while index methods (NDWI and MSWI) are mostly classified into the water and non-water information based on a threshold value, with higher total omission and commission errors at $12.45 \%, 25.64 \%, 6.38 \%$ and $12.87 \%$, respectively. Therefore, we proposed SVM as the best algorithm to identify water body and effectively detect surface water from the GF-2 image.
\end{abstract}

\section{INTRODUCTION}

Surface water is one of the vital components of the earth's environment, which is not only the essential for the survival of living beings (Vorosmarty et al. 2000), but also is the important basic information for land use/cover change (LUCC), climate changes, seasonal changes, and environmental changes throughout of the world (Alamgir et al. 2016, Araral \& Wu 2016). Therefore, knowledge of the spatial distribution of surface water is imperative for assessment of water resources, watershed changes, land surface water management and environmental monitoring (NRC 2008, Sun et al. 2012). Besides, timely monitoring and delivering data on the dynamics of surface water are essential for policy and decision-making processes (Frey et al. 2010), especially for monitoring floods risk at an emergency.

Remote sensing has advantages of the macroscopic, real-time, periodic repeatability, dynamic access to the land surface information (Lu et al. 2011), which can provide lowcost and reliable information for environmental changes at local, regional, and global scales, with their long-collected repeatable and even real-time data (Melesse et al. 2007,
Lee et al. 2018). Waterbody information, as an important constituent of remote sensing image, has become the vital national geo-information and can be automatically or semi-automatically extracted by integrating remote sensing data with geographic information systems (GIS). Meanwhile, in recent decades, accurate and effective extracting water from remote sensing data has become indispensable ways for the development and utilization of water resources (Du \& Zhou 1998), which also becomes an important branch of remote sensing applications.

Due to the ease of processing and obtaining satellite image data (Masocha et al. 2018), numerous surface water extraction algorithms have been developed and applied for remotely sensed imageries (Borton 1989), which focused on the following satellite sensors with the different spatial, temporal and spectral resolution, including the Moderate-Resolution Imaging Spectro-radio-meter (MODIS) (Khandelwal et al. 2017, Ovakoglou et al. 2016), Satellite Pour l' Observation dela Terre (SPOT) (Ji et al. 2009), Advanced Spaceborne Thermal Emission and Reflection Radiometer (ASTER) (Huang et al. 2008 ), Advanced Very High Resolution Radiometer (AVHRR) (Zhou et al. 1996), Thematic Mapper 
series data (MSS,TM,ETM+ and OLI) (Acharya et al. 2018, Alanazi \& Ghrefa 2013, Alesheikh et al. 2007, Senay et al. 2016, Wang et al. 2018, Yang et al. 2010, Zhang et al. 2016), and others (Lu et al. 2011, Peng et al. 2018, Wang et al. 2012). Besides, although many studies have been conducted most of large surface water are limited to small water bodies, such as small ponds, narrow rivers, and shallow water at the edge of rivers, which accurately cannot be extracted due to the limited spatial resolution.

In the recent decade, with the improvement of the spatial resolution, visiting time and spectral resolution of remote-sensing images, more and more high-resolution satellite data can be widely applied to extract and map surface water, such as Chinese Gaofen-1/2, Quick-Bird, WorldView, IKONOS, Rapid Eye and so on (Sawaya et al. 2003, Wasowski et al. 2012, Tatar et al. 2018). In addition, the study on water body extraction from GF-1/2 series images has become a hot research topic in China (Chen et al. 2015, Li et al. 2015, Peng et al. 2018, Song et al. 2015), though several studies have tested the performance of water indices using GF-2 sensor in China (Liu et al. 2019, Zou et al. 2019). However, this new and advanced sensor has, unfortunately, not been exploited to map surface water at county scales in Northeast China, especially at Ussuri River between China and Russia.
Hence, in this paper, the algorithms have been proposed for identifying water bodies with GF-2 including water body index methods (Normalized Difference Water Index, NDWI, Modified Shadow Water Index, MSWI), supervised classification methods (Support Vector Machine method, SVM) and others methods (Object-Oriented Method, OOM). The objectives of this study are: to apply the different methods to obtain the surface water information by comparing with water body index, SVM and OOM, to detect and map land surface water in Northeast China region qualitatively and quantitatively, to achieve the suitable method to extract surface water from the evaluation accuracy.

\section{MATERIALS AND METHODS}

\section{Study Region}

The Ussuri River is the boundary river between China and Russia (Fig. 1). The study area is located at the confluence of the Heilongjiang (Amur) River and Ussuri River, which belonged to transboundary regions and located between $47^{\circ} 53^{\prime} \mathrm{N}-48^{\circ} 10^{\prime} \mathrm{N}$ latitude and $132^{\circ} 47^{\prime} \mathrm{E}-133^{\circ} 9^{\prime}$ E longitude. It belongs to the continental monsoon climate with the annual precipitation of $532.7 \mathrm{~mm}$, the average accumulated temperature is 2435 degrees. The study region is covered by

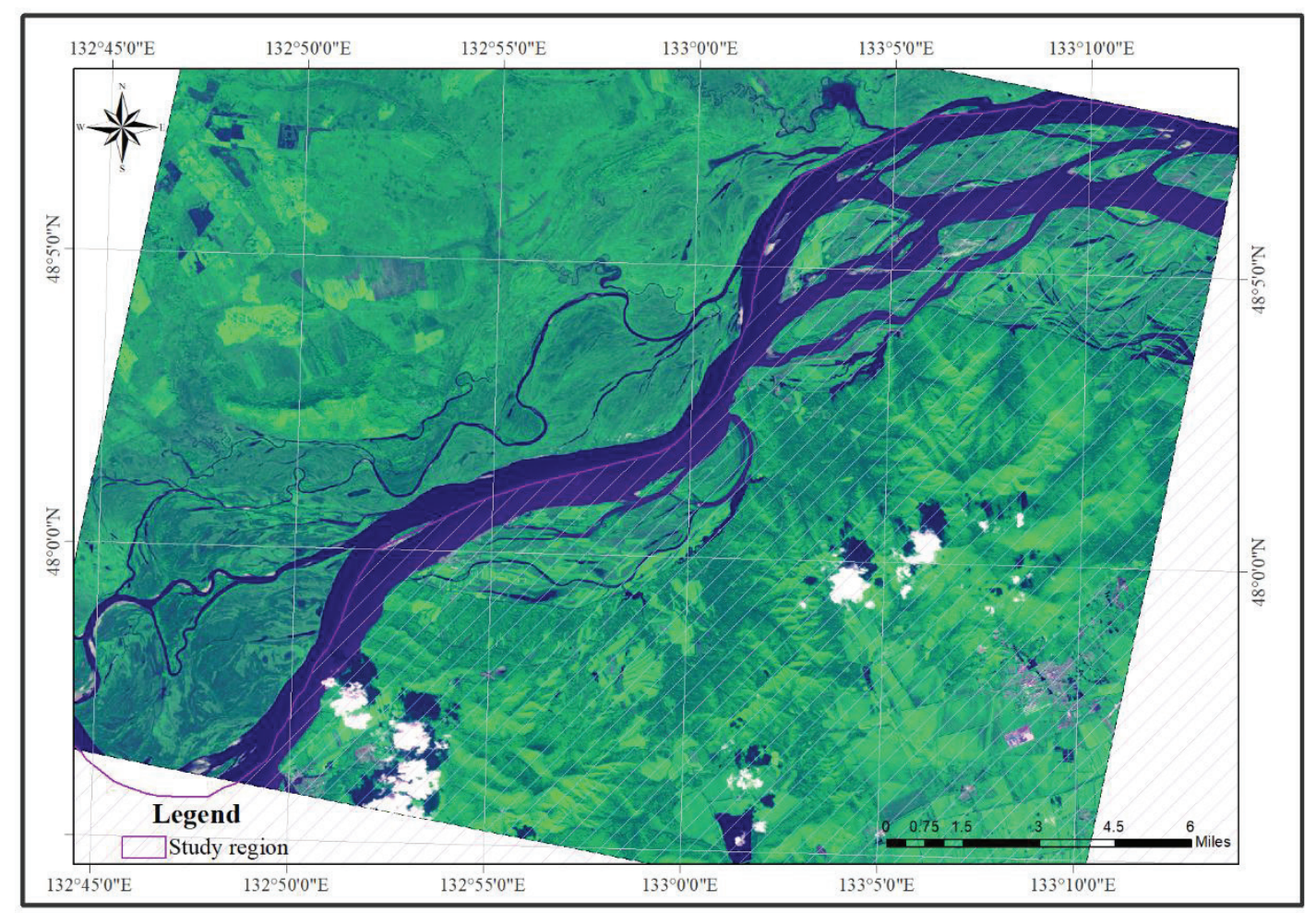

Fig. 1: Geographic location of the study region. 
marsh plain with black soil, which is suitable for all kinds of crop cultivation, and there are a small number of mountainous areas scattered in the plain, covered with forest and elevation range from $45 \mathrm{~m}$ to $65 \mathrm{~m}$, the regional terrain is high in the southwest and low in the northeast.

\section{GF-2 Image Preprocessing}

In the study, the GF-2 images (L1A products) containing a panchromatic image with a resolution of $0.8 \mathrm{~m}$ and multi-spectral image with a resolution of $4 \mathrm{~m}$, were acquired on September 12th, 2015. The parameters of the data within the study area collected are given in Table 1. Meanwhile, the high-resolution satellite imagery of GF-2 had a good quality of small cloudy and was orth-rectified by using the rational polynomial coefficient (RPC) model within remote sensing software ENVI 5.3. The average root mean square (RMS) value was less than 0.5 pixels for each image. Meanwhile, each image was projected to UTM (Zone 53N) with WGS84 datum, the ground control points were obtained from the same aerial photograph image and Google map, the multi-special data were calibrated with the radiometric calibration tool in ENVI from raw digital number (DN) to surface reflectance values, and then the atmospheric correction was applied using the Fast Line-of-Sight Atmospheric Analysis of Spectral Hypercubes (FLAASH) module.

\section{Normalized Difference Water Index (NDWI)}

Using the Landsat TM image, the normalized-difference water index (NDWI) is a normalized ratio index between green and NIR bands (Yao et al. 2015), which was first formulated by McFeeters to detect surface waters in wetland environments and measure surface water dimensions (Mcfeeters 1996). While all negative NDWI values were categorized as non-water and all positive values as water by imposing a threshold value of zero for the value of NDWI. The NDWI was calculated as follows:

$$
N D W I=\frac{T M 2-T M 4}{T M 2+T M 4}
$$

Where, TM2 represents the reflectance in green band of Landsat TM image, TM4 is the reflectance in NIR band of Landsat TM image. In this paper, TM2 and TM4 correspond to the reflectance of $B 2$ (Green band) and $B 4$ (NIR band) on GF-2 image, respectively.

\section{Modified Shadow Water Index (MSWI)}

To discriminate the water body and mountain shadow, the shadow water index (SWI) was firstly proposed by Chen Wenqian (Chen et al. 2015), which successfully eliminated the most shadow information. While to completely separate the shadow and water body, according to the former researcher, the model of MSWI was applied for the extraction of water bodies from GF-2, which is defined in Eq. 2.

$$
M S W I=\left(B_{1}-B_{4}\right) / B_{4}\left\{\begin{array}{l}
<N(\text { Shade }) \\
\geq N(\text { Waterbody })
\end{array}\right.
$$

Where, $B_{1}$ and $B_{4}$ represent the reflectance in the blue band and NIR band on GF-2 image, respectively. $N$ is the experimental threshold of the water body in the study region, which can discriminate between water and non-water and need a lot of experiments and visual comparison.

\section{Support Vector Machine (SVM)}

SVM is a supervised learning system and is based on recent improvements in statistical learning theory (Cristianini \& Shawe 2000). Due to this method with the advantage of minimizer errors and maximiser, the geometric characteristics of edge areas, multi-class support vector machine (SVM) classification for water body extraction and coastline detection has been commonly used by many researchers (Nath et al. 2010, Sarp \& Ozcelik 2016, Zhang et al. 2013). However, the research for water extraction on GF-2 image is less, therefore,

Table 1: The major parameters of the GF-2 image.

\begin{tabular}{|lll|}
\hline Parameter & Resolution panchromatic/resolution multi-spectral camera \\
\hline Spectral range & Panchromatic & $0.45-0.90 \mu \mathrm{m}$ \\
& Multi-spectral & $0.45-0.52 \mu \mathrm{m}$ \\
& & $0.52-0.59 \mu \mathrm{m}$ \\
& & $0.63-0.69 \mu \mathrm{m}$ \\
Spatial resolution & & $0.77-0.89 \mu \mathrm{m}$ \\
& Panchromatic & $0.8 \mathrm{~m}$ \\
Width & Multi-spectral & $4 \mathrm{~m}$ \\
Revisit period (when sideway) & & $45 \mathrm{~km}$ \\
\hline
\end{tabular}


in this paper, SVM with kernel function and regularization parameters was used as a quantitative method to extract the water body form the GF-2 image.

\section{Object-Oriented Method (OOM)}

In contrast to pixel-based image classification techniques, object-based image analysis methods provide additional information that can be used to improve the discrimination of land cover classes (Yan et al. 2006), which were discussed by several researchers for water body extraction (Kaplan et al. 2017, He et al. 2016, Yue et al. 2010), especially using object-oriented segmentation and classification methods for automated delineation of lakes (Johansson et al. 2013, Rishikeshan et al. 2018, Selmes et al. 2011). While using Feature Extraction (FE) module remote software ENVI 5.3 in this study area, an object-oriented classification method was utilized to segment the GF-2 image into small objects and to obtain the water body information.

\section{RESULTS AND DISCUSSION}

\section{Water Maps Analysis}

Visually, applying by the four water extraction methods in the study region, the Fig. 2 not only shown the similar patterns of water bodies but also lighted the differences between water and non-water areas. NDWI separates water and non-water objects well at the large scale of surface water region, which can keep the integrity of large river water information with a clear and accurate boundary outline. However, in the region of shadows and artificial building areas, dark shadows and water were often misidentified by water indices of NDWI (Yao et al. 2015), where the accuracy of water information acquiring was low and could not eliminate the effects of shadows. In this paper, a series of experimental thresholds of MSWI between water and non-water areas were firstly tested to generate the water body, then combing MSWI with DEM data to extract water body from the GF-2 image in the study region. It seems that MSWI can effectively distinguish water from non-water surfaces and keep the continuity and integrity for a large water body in some degree, which can eliminate some shallows of building-up land and unused land with lower commission errors. However, the discontinuities outline of the small river still occurs. NDWI and MSWI images classified into the water and non-water information based on threshold value selection, the threshold value of water region for NDWI is greater than zero, whereas threshold value on MSWI is near to -0.5. The extraction results of NDWI and MSWI models are not very good, because they not only can often mistakenly identify shadow as water bodies, but also can completely omit some of the small water regions (small ponds, narrow rivers, and shallow water) from GF-2 images using a lower threshold. SVM, based on the image pixel level and spectral characteristics of remote sensing image,

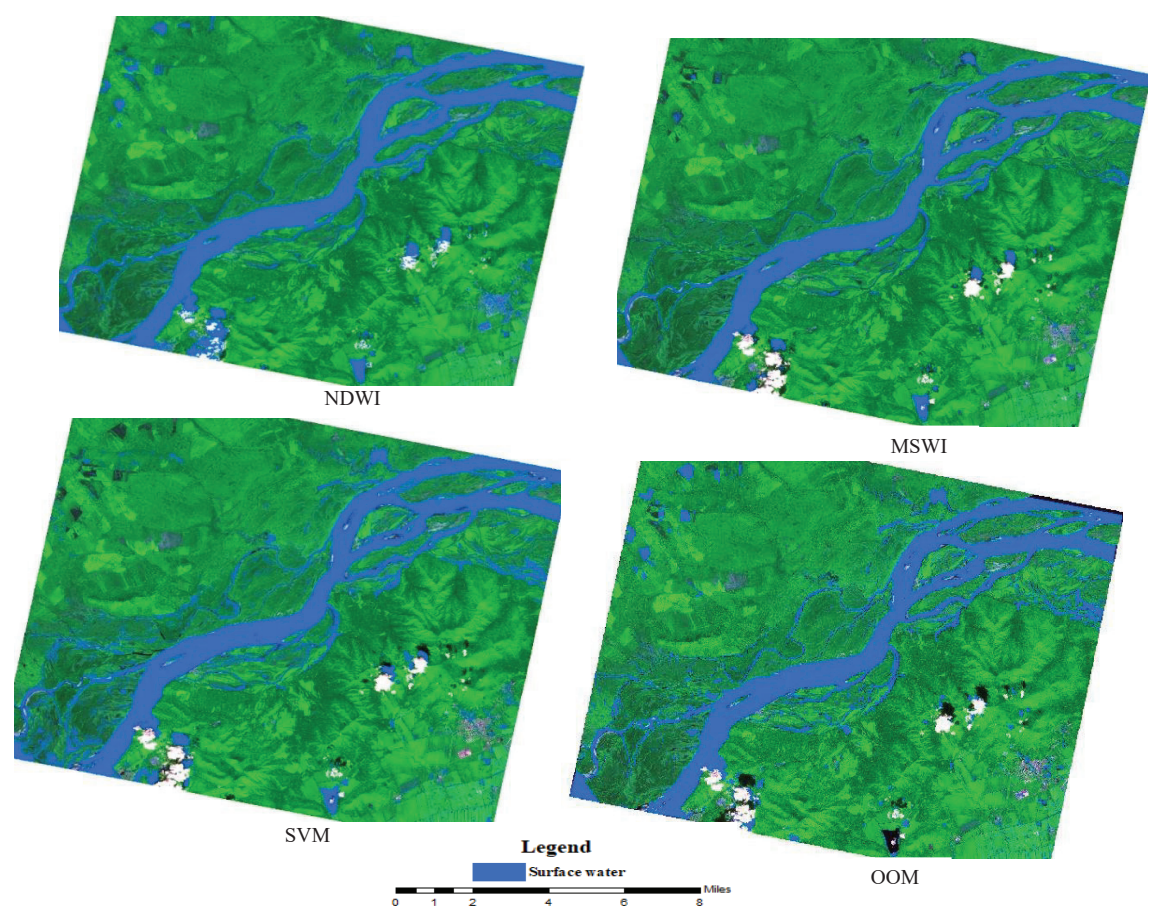

Fig. 2: Results of surface water information extraction for 4 methods from GF-2 image. 
is applied to extract the water body by selecting the training samples. Comparing to the NDWI and MSWI, SVM can well and effectively offer a complete water map for study area from the GF-2 by lowering the mixing of water and non-water in small rivers, small ponds, bare land and shallow areas. Besides, it can increase the accuracy of the water body extraction by fewer impacts on shadows and artificial building areas. OOM, using the spectral and spatial texture information during the process of multi-scale segmentation (Sun et al. 2018), keeps the maximum homogeneity between water and non-water information, and exactly identify water body with slightly smoother in water boundary, which avoids the phenomenon of "salt and pepper" and can detect the small ponds and rivers. However, the phenomenon of broken lines for small river still occurred. Furthermore, SVM and OOM methods can extract small ponds and small waters with complete shapes from GF-2 data, whereas NDWI and MSWI can mostly omit them.

\section{No-water Information Analysis}

In this paper, the unused land (mining wasteland), building-up land and shadow area were selected as the typical samples to analyse the impact on water body extraction methods. A total of 200 pure pixels were selected from the GF-2 imagery for each type, which are shown in Fig. 3. As far as the unused land is concerned, the commission errors of NDWI were most serious, in which some land was almost mistakenly classified by water body, whereas a part of unused land was misclassified as surface water by MSWI. In contrast, the performance of SVM and OOM is better than that of NDWI and MSWI. In fact, the influence on water body extraction accuracy of NDWI and MSWI, a suitable threshold value selection is applied. In order to modify the classification errors in water extraction, in next step, the best way for NDWI and MSWI is to select the optimum threshold values. The Fig. 3 showed that nearly all the regions of built-up land were mistakenly identified as water bodies with the worst commission errors by using NDWI, followed by MSWI. It is possible to describe built-up areas as surface water due to the similar positive index values, while SVM and OOM are superior to that of NDWI and MSWI. It seems that SVM and OOM can effectively suppress the built-up land noises which were easily misidentified by NDWI and MSWI, and OOM showed the best results for the artificial construction, whereas a very small number of building shadows were wrongly identified as water bodies. From various water body extraction models in this study, the shadow areas are wrongly classified into water information at different levels. Compared with all the methods, the NDWI had mistaken all the shadow regions into water bodies and showed the worst water extraction accuracy, followed by MSWI. On the contrary, the OOM showed the highest accuracy by mistakenly classifying shadows into surface water on shadow regions, the presence of shadows in the images may cause misclassification due to similar spectral reflectance patterns as water body areas (Sarp \& Ozcelik 2016), while it indicated that the OOM was more vulnerable to shadow pixels than the other method in some way.

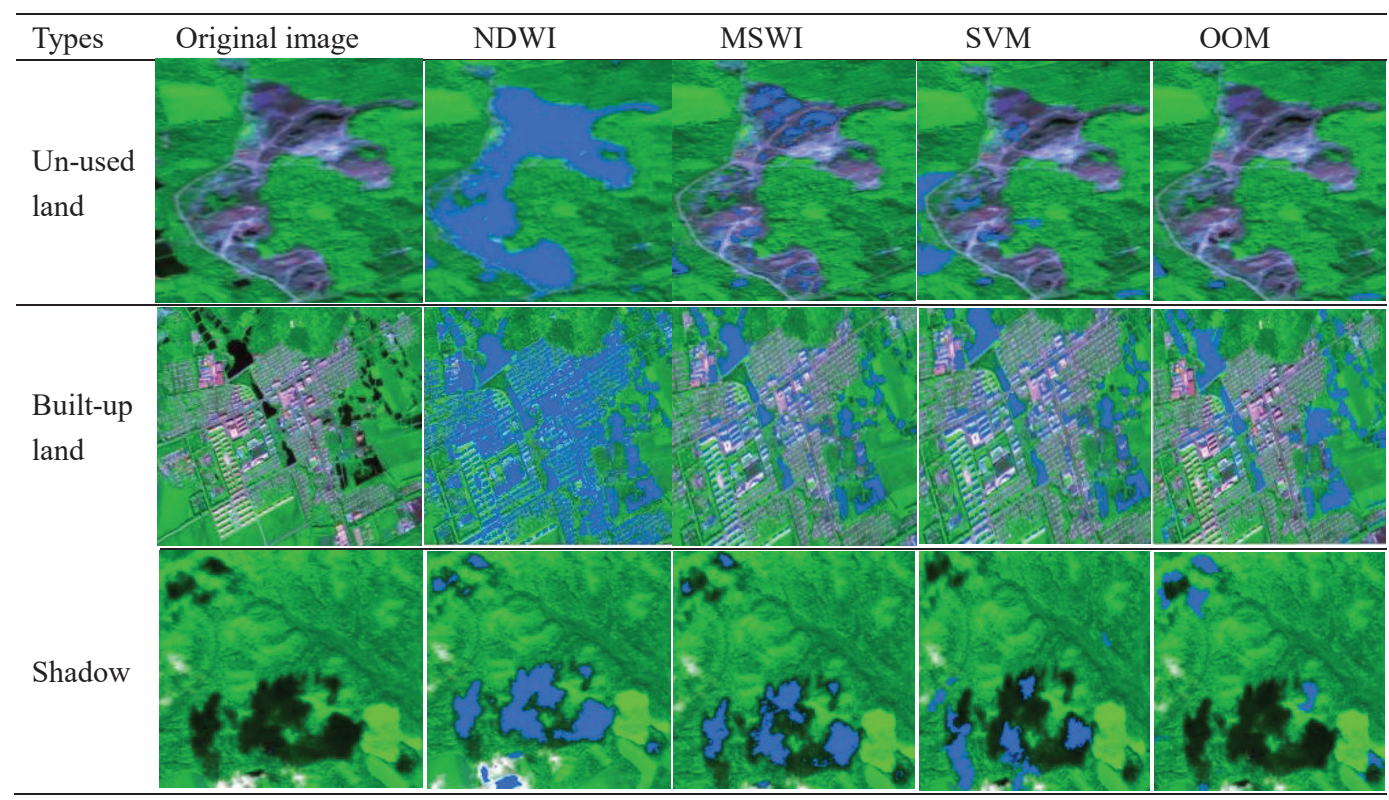

Fig. 3: Detail contrast of water extraction results from no-water objects. 


\section{Water Extraction Accuracy}

To test the accuracy of the water extraction in different models, we used images with the Gram-Schmidt spectral sharpening method to obtain the higher resolution image of $0.8 \mathrm{~m}$. According to the scope of the research region within Chinese territory, combing the field survey data of water and non-water with GPS information (Garmin) of the study area, we examined 60 selected check-points (Fig. 4). Meanwhile, the water extraction information was applied to the ArcGIS 10.3 as the background data, we imported the field data into the ArcGIS software as the ground truth in shape format, based on the confusion matrix method, four accuracy measures are applied to evaluate the performance of water indices including overall accuracy and kappa coefficient. Compared to the results of different water extraction methods, the accuracy evaluations of the GF-2'S results are listed in Table 2.

The Table 2 shows that the accuracy assessment of water extraction methods, in which the SVM gave the highest overall accuracy of $94.68 \%$ and with Kappa coefficient at 0.87 , followed by OOM, with overall accuracy and Kappa coefficient of $93.57 \%$ and 0.85 , respectively, while the NDWI showed the worst overall accuracy at $89.35 \%$, with Kappa coefficient of 0.78 . In addition, the SVM showed the best performance with the highest accuracy in water extraction, followed by the OOM, which have the $1.11 \%$ and 0.02 higher than those of the OOM for overall accuracy and Kappa coefficient, respectively. Meanwhile, the third highest accuracy was the MSWI at $92.56 \%$ of overall accuracy and at 0.82 of the Kappa coefficient.

The properties of surface water vary with seasonal and even daily changes, due to the angle of the sun, radiation hours and atmospheric composition impacts (Feyisa et al. 2014, Yang et al. 2015a, 2015b). Compared with other water extraction methods in this test site,the NDWI can quickly extract water body information form the GF-2 image, wherea performed the worst surface water extraction accuracy at $89.35 \%$. In addition, the surface water total errors of omission and commission were lowest at $12.45 \%$ and $25.64 \%$, respectively (Table 3 ). Especially in the region of building areas, shadows and unused land were wrongly identified as surface water. According to the previous research ( $\mathrm{Ji}$ et al. 2015, Xiong et al. 2018, Masocha et al. 2018), it seems that NDWI was suitable for simple water body extraction in multi-spectral $30 \mathrm{~m}$ resolution image of Landsat TM and

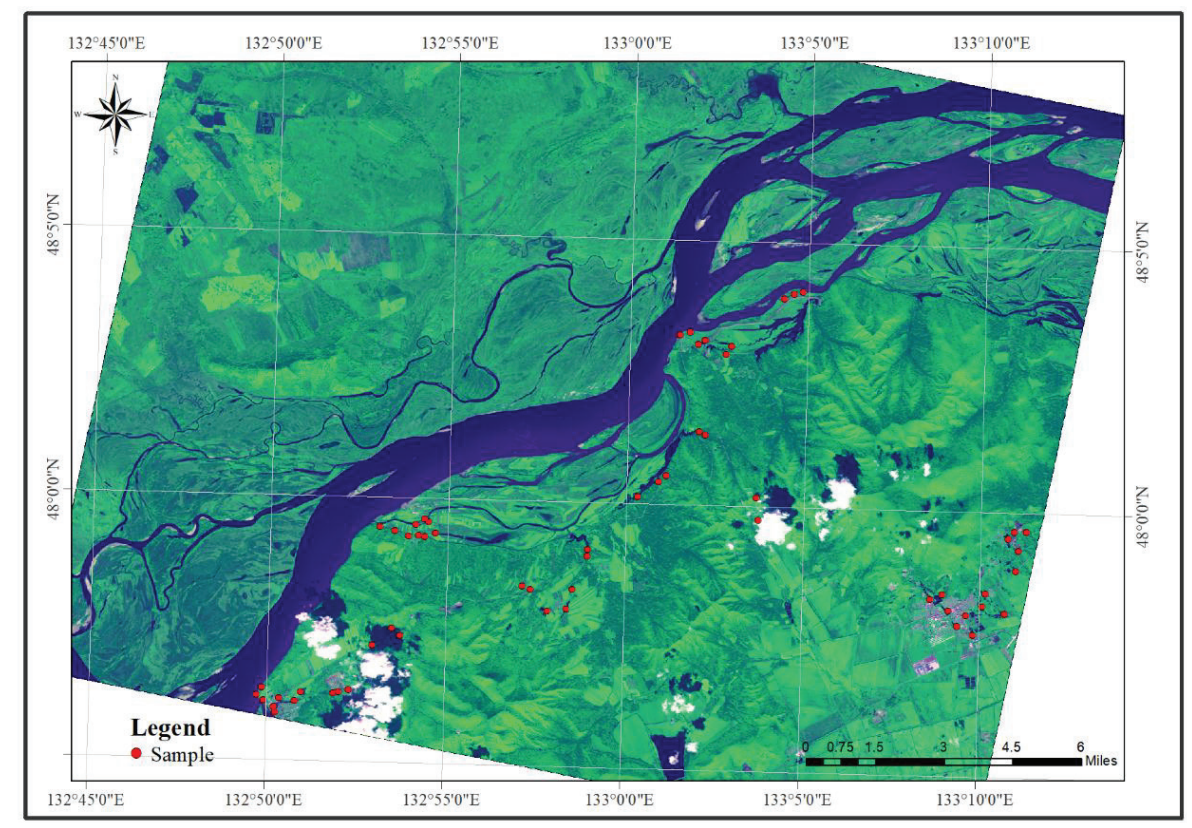

Fig. 4: Distribution map of survey sample in the study region.

Table 2: Accuracy comparison of five classification methods.

\begin{tabular}{|lllll|}
\hline Methods & NDWI & MSWI & SVM & OOM \\
\hline overall accuracy $1 \%$ & 89.35 & 92.56 & 94.68 & 93.57 \\
Kappa coefficient & 0.78 & 0.82 & 0.87 & 0.85 \\
\hline
\end{tabular}


Table 3: Water extraction accuracy assessment for the study region E: errors (C, commission; O, omission).

\begin{tabular}{|llll|}
\hline Number & Land surface water information extraction methods & Ec & Eo \\
\hline 1 & NDWI & $25.64 \%$ & $12.45 \%$ \\
2 & MSWI & $12.87 \%$ & $6.38 \%$ \\
3 & SVM & $6.75 \%$ & $5.31 \%$ \\
4 & OOM & $6.43 \%$ & $6.15 \%$ \\
\hline
\end{tabular}

moderate-resolution image of MODIS data by band calculations; whereas it could realize the surface water automation extraction under the demands of lower accuracy, we can conclude that NDWI was not recommended to obtain water body in GF-2 images.

The total omission and commission errors of MSWI at $6.38 \%$ and $32.87 \%$, respectively, compared to the NDWI, the MSWI not only extracted the small and tiny water bodies with the faster speed but also kept the complete shape of water that conformed to the actual geographical distribution, which can quickly obtain the surface water from remote sensing data and is suitable for hydrological emergency monitoring. However, this algorithm cannot distinguish between shadow pixels and water pixel in some regions. Also, the water extraction accuracy mainly relies on the experimental threshold value selection which is influenced by the subjective judgment of the researcher. Demands for lower accuracy of water monitoring and water emergency like flood risks, we propose this method for extracting surface water.

SVM, with the total omission and commission errors of $5.31 \%$ and $6.75 \%$, respectively, can improve the water extraction accuracy and speed from GF-2 images, we propose this method as the best way to identify water bodies and effectively detect surface water in the study region. Great influence on water extraction speed of this model is related to the number of sample selections, while some region associated with classifying mixed pixels of shadow occurred the small omission errors.

The total omission and commission errors of OOM were similar to that of SVM, the water extraction results of OOM also could supply the demands for the department of water administration in detecting surface water. However, during the water extraction procession from high-resolution remote sensing image, applying the segmentation level and the merging level was mostly evaluated by the experimental threshold, comparing with SVM, which is greatly affected by manual interventions and cost more time with lower inefficiency. Therefore, it was not available for water body extraction and detecting surface water in the emergency. Although applying the Chinese high-resolution images to study water body extraction was relatively less, in the future, we would make full use of the spatial, spectral and texture attributes of GF-2 multi-spectral high-resolution and apply new algorithm to extract water body, especially focused on the panchromatic image.

\section{CONCLUSIONS}

In this paper, the boundary river of Ussuri River of Tongjiang section between China and Russia was taken as the research region. Using GF-2 multi-spectral high-resolution remote sensing imagery of China government, we conducted the study by applying four methods for surface water extraction. Our results showed that all the models can extract large water body information to some degree, the results of NDWI models are not very good because some small water bodies could not be effectively extracted from GF-2 images. On the countrary, the performances of surface water extraction of study region indicate that the methods of SVM and OOM are suitable for detecting and updating surface water bodies from GF-2 images when compared to the other indices. We can conclude that NDWI methods are suitable for surface water extraction from Landsat TM or MODIS images.

Compared with classification results of a water body, SVM algorithms can extract surface water information more accurately than the other methods, which gives the highest overall accuracy of $94.68 \%$ and with Kappa coefficient at 0.87 , followed by OOM. While the NDWI can quickly extract water body information form the GF-2 image, which owes the highest omission and commission errors of $12.45 \%$ and $55.64 \%$, respectively, followed by MSWI. Therefore, we proposed the SVM method as the best way to identify the water body and to effectively detect surface water in the study region. Further study is needed in GF- 2 image for water information extraction in the future, we would make full use of the spatial, spectral and texture attributes of GF-2 multi-spectral high-resolution and apply new algorithm to extract water bodies, especially focused on the panchromatic image.

\section{ACKNOWLEDGEMENT}

We appreciate the staff of the platform for Wuzhishan Ecological Station, 3S laboratory of Hainan University and Key Laboratory of Germplasm Resources of Tropical Special Ornamental Plants of Hainan Province and Haikou Urban Forestry Engineering Techn ology Development and Research 
Center. We We thank International English teacher Steve Harding for his assistance in language editing. We also want to express our respect and thanks to the anonymous reviewers and the editors for their helpful comments in improving the quality of this paper. This research was supported by National High Technology Research and Development Program 863 (Grant No.2012AA102001), Natural Science Foundation of Hainan University (Grant No. KYQD (ZR) 20058 and 1863), and Natural Scientific Foundation of Heilongjiang Province (Grant No. D201410).

\section{REFERENCES}

Acharya, T., Subedi, A. and Lee. D. 2018. Evaluation of water indices for surface water extraction in a Landsat 8 Scene of Nepal. Sensors, 18: 2580; doi:10.3390/s18082580.

Alamgir, A., Khan, M.A., Manino, I., Shaukat, S.S. and Shahab, S. 2016. Vulnerability to climate change of surface water resources of coastal areas of Sindh, Pakistan. Desalin. Water. Treat., 57: 18668-18678.

Alanazi, H.A. and Ghrefat, H.A. 2013. Spectral analysis of multispectral Landsat7ETM+ and ASTER data for mapping land cover at Qurayah Sabkha, Northern Saudi Arabia. J. Indian. Soc. Remote Sens., 41(4): 833-844.

Alesheikh, A.A., Ghorbanali, A. and Nouri, N. 2007. Coastline change detection using remote sensing. Int. J. Environ. Sci. Technol., 4: 61-66.

Araral, E. and Wu, X. 2016. Comparing water resources management in China and India policy design: institutional structure and governance. Water Policy, 18: 1-13.

Borton, I.J. 1989. Monitoring floods with AVHRR. Remote Sens. Environ., 30(1): 89-94.

Chen, W.Q., Ding, J.L., Li, Y.H. and Niu, Z.Y. 2015. Extraction of water information based on China-made GF-1 remote sense image. Resources Science, 37(6): 1166-1172.

Cristianini, N. and Shawe, T.J. 2000. An Introduction To Support Vector Machines and Other Kernel Based Learning Methods. Cambridge University Press. http://dx.doi.org/10.1017/CBO9780511801389.

Du, Z.Y. and Zhou, C.H. 1998. Automatically water extraction remote sensing information for water bodies. Journal of Remote Sensing, 4: 264-269.

Feyisa, G.L., Meilby, H., Fensholt, R. and Proud, S. R. 2014. Automated water extraction index: a new technique for surface water mapping using Landsat imagery. Remote Sens. Environ., 140: 23-35.

Frey, H., Huggel, C., Paul, F. and Haeberli, W. 2010. Automated detection of glacier lakes based on remote sensing in view of assessing associated hazard potentials. Grazer Schriften der Geographie und Raumforschung, 45: 261-272.

He, Y.R., Zhang, X.X. and Hua, L.Z. 2016. Object-based distinction between building shadow and water in high resolution imagery using fuzzy-rule classification and artificial bee colony optimization. J. Sens., https:// doi.org/10.1155/2016/2385039.

He, Z.Y., Zhang, X.C., Huang, Z.C. and Jiang, H.X. 2004. A water extraction technique based on high-spatial resolution remote sensing images. J. Zhejiang. Univ. (Sci. Edu.), 31(6): 701-707.

Huang, H.B., Zhao, P., Chen, Z.Y. and Guo. W. 2008. Research on the method of extracting water body information from ASTER Remote Sensing image. Remote Sensing Technology and Application, 23(5): 525-528.

Ji, L., Geng, X., Sun, K., Zhao, Y. and Peng, C. 2015. Target detection method for water mapping using Landsat 8 OLI/TIRS imagery. Water, 7: 794-817.

Ji, L., Zhang, L. and Mylie, B. 2009. Analysis of dynamic thresholds for the normalized difference water index. Photogramm. Eng. Rem. S., 75(11): 1307-1317.
Johansson, A.M. and Brown, I.A. 2013. Adaptive classification of supra-glacial lakes on the West Greenland Ice Sheet. IEEE J. Sel. Top. Appl. Earth Obs. Remote Sens., 6: 1998-2007.

Kaplan, G. and Avdan, U. 2017. Object-based water body extraction model using Sentinel-2 satellite imagery. Eur. J. Remote Sens., 50(1):143-150.

Khandelwal, A., Karpatne, A., Marlier, M.E., Kim, J., Lettenmaier, D.P. and Kumar, V. 2017. An approach for global monitoring of surface water extent variations in reservoirs using MODIS data. Remote Sens. Environ., http://dx.doi.org/10.1016/j.rse.2017.05.039.

Lee, J.K., Acharya, T.D. and Lee, D.H. 2018. Exploring land cover classification accuracy of Landsat 8 image using spectral index layer stacking in hilly region of South Korea. Sens. Mater., 30: 1-15.

Li, Y.H., Ding, J.L. and Yan, R.H. 2015. Extraction of small river information based on China-made GF-1 remote sense images. Resources Science, 37(2): 408-416.

Liu, S.T., Wang, M.X., Yang, S.W., Yan, M.Z. and Yang, L.H. 2019. Extraction accuracy and stability analysis of different water body index models in GF-2 images. Bulletin of Surveying and Mapping, 8: 135-139.

Lu, S.L., Wu, B.F., Yan, N.N. and Wang, H. 2011. Water body mapping method with HJ-1A/B satellite imagery. Int. J. App. Earth Obs., 13: 428-434.

Masocha, M., Dube, T., Makore, M., Shekede, M.D. and Funani, J. 2018. Surface water bodies mapping in Zimbabwe using Landsat 8 OLI multispectral imagery: A comparison of multiple water indices. Physics and Chemistry of the Earth, Parts A/B/C, 106: 63-67.

Mcfeeters, S. K. 1996. The use of normalized difference water index (NDWI) in the delineation of open water features. Int. J. Remote Sens., 17(7): $1425-1432$.

Melesse, A.M., Weng, Q., Thenkabail, P.S. and Senay, G.B. 2007. Remote sensing sensors and applications in environmental resources mapping and modelling. Sensors, 7: 3209-3241.

Nath, R.K. and Deb, S.K. 2010.Water-body area extraction from high resolution satellite images-an introduction, review, and comparison. Int. J. Image Process., 3: 353-372.

National Research Council, 2008. Integrating Multiscale Observations of U.S. Waters. The National Academies Press, Washington, DC, USA.

Ovakoglou, G., Alexandridis, T.K., Crisman, T.L., Skoulikaris, C. and Vergos, G.S. 2016. Use of MODIS satellite images for detailed lake morphometry: application to basins with large water level fluctuations. Int. J. Appl. Earth Obs., 51: 37-46.

Peng, B.F., Chen, Z.F., Li, J.H., Luo, W.J., Gan, J. and Zeng, R.L. 2018. Monitoring water quality of Dongting Lake region based on GF-1 image. Geographical Research. DOI: 10.11821/dlyj201809002

Rishikeshan, C.A. and Ramesh, H. 2018. An automated mathematical morphology driven algorithm for water body extraction from remotely sensed images. Isprs. J. Photogramm., 146: 11-21.

Sarp, G. and Ozcelik, M. 2016. Water body extraction and change detection using time series: A case study of Lake Burdur, Turkey. Journal of Taibah University for Science, 11: 381-391.

Sawaya, K.E., Olmanson, L.G., Heinert, N. J., Brezonik, P.L. and Bauer, M.E. 2003. Extending satellite remote sensing to local scales: land and water resource monitoring using high-resolution imagery. Remote Sensing of Environment, 88(1-2): 144-156.

Selmes, N., Murray, T. and James, T.D. 2011. Fast draining lakes on the green land ice sheet linked to routing of surface water. Geophys. Res. Lett. 38. https://doi.org/10.1029/2011GL047872.

Senay, G.B., Friedrichs, M.K., Singh, R.K. and Velpuri, N.M. 2016. Evaluating Landsat 8 evapotranspiration for water use mapping in the Colorado River Basin. Remote Sens. Environ.,185: 171-185.

Song, Y.B., Jin, Y.T. and Lang, F. 2015. Water extraction based on multispectral data of GF-1 satellite. Journal of North China Institute of Aerospace Engineering, 25(1): 16-19.

Sun, F., Sun, W., Chen, J. and Gong, P. 2012. Comparison and improvement of methods for identifying waterbodies in remotely sensed imagery. Int. J. Remote Sens., 33: 6854-6875. 
Sun, Na., Zhu, W.N. and Cheng, Q. 2018. GF-1 and Landsat observed a 40-year wetland spatiotemporal variation and its coupled environmental factors in Yangtze river estuary. Estuar. Coast. Shelf. S., 207: 30-39.

Tatar, N., Saadatseresht, M., Arefi, H. and Hadavand. A. 2018. A robust object-based shadow detection method for cloud-free high resolution satellite images over urban areas and water bodies. Advances in Space Research, 61(11): 2787-2800.

Vorosmarty, C.J., Green, P., Salisbury, J. and Lammers, R.B. 2000. Global water resources: Vulnerability from climate change and population growth. Science, 289: 284-288.

Wang, Q.Y., Chen, R.X., Xu, J. and Chen, X.L. 2012. Research on methods for extracting water body information from HJ-1A/B Data. Science Technology and Engineering, 12(13): 3051-3056.

Wang, X.B., Xie, S.P., Zhang, X.L., Chen, C., Guo, H., Du, J.K. and Duan, Z. 2018. A robust multi-band water index (MBWI) for automated extraction of surface water from Landsat 8 OLI imagery. Int. J. Appl. Earth Obs., 68: 73-91.

Wasowski, J., Lamanna, C., Gigante, G. and Casarano, D. 2012. High resolution satellite imagery analysis for inferring surface-subsurface water relationships in unstable slopes. Remote Sensing of Environment, 124: 135-148.

Xiong, L.H., Deng, R., Li, J., Liu, X.L., Qin, Y., Liang, Y.H. and Liu, Y.F. 2018. Subpixel surface water extraction (SSWE) using Landsat 8 OLI Data. Water, 10. doi:10.3390/w100506531.

Yang, K., Li, M.C., Liu, Y.X., Cheng, L., Huang, Q.H. and Chen, Y.M. 2015a. River detection in remotely sensed imagery using Gabor filtering and path opening. Remote Sens., 7: 8779-8802.

Yan, G., Mas, J., Maathuis, B.H.P., Zhang, X.M. and Van, D.P. 2006.
Comparison of pixel-based and object oriented image classification approaches-a case study in a coal fire area, Wuda, Inner Mongolia, China. Int. J. Remote Sens., 27(18): 4039-4055.

Yang, S.W., Xue, C.S. and Liu, T. 2010. A method of small water information automatic extraction from TM remote sensing images. Acta Geodaetica et Cartographica Sinica, 39(6): 611-617 (in Chinese).

Yang, Y.H., Liu, Y.X., Zhou, M.X., Zhang, S.Y., Zhan, W.F., Sun, C. and Duan, Y.W. 2015b.Landsat 8 OLI image based terrestrial water extraction from heterogeneous back-grounds using a reflectance homogenization approach. Remote Sens. Environ., 171: 14-32.

Yao, F.F., Wang, C., Dong, D., Luo, J.C., Shen, Z.F. and Yang, K.H. 2015. High-resolution mapping of urban surface water using ZY-3 multi-spectral imagery. Remote Sens., doi: 10.3390/rs70912336.

Yue, Y., Gong, J. and Wang, D. 2010. The extraction of water information based on SPOT5 image using object-oriented method. In: 2010 18th International Conference on Geoinformatics, pp. 1-5, IEEE.

Zhang, F., Tiyip, T., Kung, H., Johnson, V. C., Wang, J. and Nurmemet, I. 2016. Improved water extraction using Landsat TM/ETM images in Ebinur Lake, Xinjiang, China. Remote Sensing Applications: Society and Environment, 4: 109-118.

Zhang, H., Jiang, Q.G. and Xu, J. 2013. Coastline extraction using support vector machine from remote sensing image. Journal of Multimedia, DOI: $10.4304 / j m m .8 .2 .175-182$.

Zhou, C.H., Du, Y.Y. and Luo, J.C.1996. A description model based on knowledge for automatically recognizing water from NOAA/AVHRR. Journal of Natural Disaster, 5(3): 100-108.

Zou, C., Yang, X.Z., Dong, Z.Y. and Wang. D. 2019. A fast water information extraction method based on GF-2 remote sensing image. Journal of Graphics, 40(1): 99-104. 